\title{
Breast Tissue Expander
}

National Cancer Institute

\section{Source}

National Cancer Institute. Breast Tissue Expander. NCI Thesaurus. Code C85840.

An inflatable reservoir that is used to expand the remaining breast skin after a

mastectomy and prior to surgical reconstruction. 